CLINICAL STUDY

\title{
Geographic variations in the frequency of thyroid disorders and thyroid peroxidase antibodies in persons without former thyroid disease within Germany
}

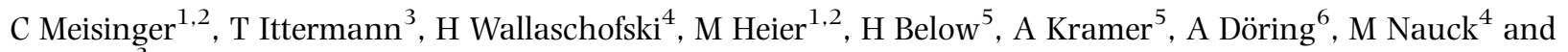 \\ H Völzke ${ }^{3}$ \\ ${ }^{1}$ Helmholtz Zentrum München, Institute of Epidemiology II, German Research Center for Environmental Health (GmbH), Neuherberg, Germany, \\ ${ }^{2}$ Central Hospital of Augsburg, MONICA/KORA Myocardial Infarction Registry, Stenglinstr. 2, D-86156 Augsburg, Germany, ${ }^{3}$ Institute for Community \\ Medicine, University of Greifswald, Greifswald, Germany, ${ }^{4}$ Institute of Clinical Chemistry and Laboratory Medicine, University of Greifswald, Greifswald, \\ Germany, ${ }^{5}$ Institute of Hygiene and Environmental Medicine, University of Greifswald, Greifswald, Germany and ${ }^{6}$ Helmholtz Zentrum München, Institute \\ of Epidemiology I, German Research Center for Environmental Health (GmbH), Neuherberg, Germany \\ (Correspondence should be addressed to C Meisinger at Central Hospital of Augsburg, MONICA/KORA Myocardial Infarction Registry; \\ Email: christa.meisinger@helmholtz-muenchen.de)
}

\begin{abstract}
Objective: To investigate regional variations in the frequency of undiagnosed thyroid disorders among 25- to 88-year-old men and women in two communities in the northeast and the south of Germany. In addition, autoantibodies to thyroperoxidase (TPO-Abs) and urinary iodine excretion were determined. Methods: Two population-based surveys of men and women using a common standardized protocol, the Study of Health in Pomerania (SHIP) in the northeast of Germany (2505 participants) and the Kooperative Gesundheitsforschung in der Region Augsburg (KORA) in the south of Germany (2316 participants), were compared with regard to the frequency of undiagnosed thyroid disorders. Results: Compared with the northeast of Germany, urinary iodine excretion and serum thyroidstimulating hormone (TSH) levels were significantly higher in the south. The median urinary iodine concentration was $110 \mu \mathrm{g} / \mathrm{l}(64 ; 169 \mu \mathrm{g} / \mathrm{l})$ in SHIP and $151 \mu \mathrm{g} / \mathrm{l}(97 ; 214 \mu \mathrm{g} / \mathrm{l})$ in KORA, and the median TSH value was $0.81 \mathrm{mIU} / \mathrm{l}(0.56 ; 1.15 \mathrm{mIU} / \mathrm{l})$ in SHIP and $1.22 \mathrm{mIU} / \mathrm{l}(0.84 ; 1.80 \mathrm{mIU} / \mathrm{l}) \mathrm{in}$ KORA. The frequency of elevated TSH (TSH $\geq 2.12 \mathrm{mIU} / \mathrm{l}$ ) was $4.3 \%$ in SHIP and $14.1 \%$ in KORA $(P<0.001)$; the corresponding values for suppressed TSH $(<0.25 \mathrm{mIU} / \mathrm{l})$ were 3.5 and $1.7 \%$ $(P<0.001)$. The proportion of ultrasonographic findings was $55.5 \%$ in SHIP and $68.0 \%$ in KORA. The frequency of serum TPO-Abs did not differ significantly between northeast and south Germany. Conclusions: There were considerable regional disparities in the frequency of thyroid disorders within Germany. These differences can be explained not only by different regional histories of natural iodine deficiency but also by current differences in the iodine supply under an identical nationwide iodine fortification program.
\end{abstract}

European Journal of Endocrinology 167 363-371

\section{Introduction}

Thyroid disorders such as goiter, nodules, autoimmune thyroid disease, and thyroid dysfunction affect a considerable portion of the population $(1,2)$. The spectrum of thyroid disorders depends on ethnic and environmental factors, especially on iodine intake $(3,4,5)$. For years, iodine intake of many European populations was below the level recommended by international organizations (6). Until the mid 1990s, Germany was generally considered an iodine-deficient area (7). Iodine supply varied within Germany: while the north-eastern part of Germany was an area with a moderate iodine deficiency, the iodine deficiency was moderate to severe in south Germany $(8,9)$.
Since the beginning of the 1980s, a voluntary iodine supply program has been introduced stepwise to decrease the prevalence of iodine deficiency disorders (10). The activities differed between the eastern and western parts of Germany (11). In 1983, a general iodine fortification program was implemented in the eastern part, but iodine deficiency could not be corrected until 1989, and after reunification, this effect was initially lost. In 1993, by law a regulation concerning the iodization of table salt became effective, which led to an increase in the use of iodized salt for food production. Thus, during the past 15 years, the iodine supply in Germany remained stable. A nationwide iodine survey conducted in children found that the median urinary iodine concentrations were in the lower section of the recommended range, suggesting 
that iodine supply has considerably improved. Consequently, clear-cut regional gradients in iodine supply within Germany have not been present anymore, but the nationwide survey had limited power to explore the iodine supply in distinct regions (12).

In the present paper, we analyzed data from two large population-based surveys in adults, the Study of Health in Pomerania (SHIP-1) in the northeast and the Kooperative Gesundheitsforschung in der Region Augsburg (KORA F4) study in the south of Germany. Both studies, conducted in two selected regions, were carried out almost concurrently using standardized examination methods. The purpose of the present study was to investigate regional variations in the iodine supply and the frequency of undiagnosed thyroid disorders, including thyroid dysfunction, goiter, nodules, and autoimmune thyroid disease among 25- to 88-year-old men and women without thyroid disease within Germany.

\section{Materials and methods}

\section{Study population}

Kooperative Gesundheitsforschung in der Region Augsburg F4 Data are based on the KORA F4 study (2006-2008), a follow-up of the KORA S4 study, a population-based health survey conducted in the city of Augsburg and in two surrounding counties between 1999 and 2001. For the S4 study, a total sample of 6640 subjects was drawn by a two-stage cluster sampling method from the target population consisting of all German residents of the region aged 25-74 years. Of all 4261 participants of the S4 baseline study, 3080 also participated in the follow-up F4 study (response $79.6 \%$ ) (13). After exclusion of 764 participants (24.8\%; 570 women, 194 men) with known thyroid disease (e.g. hyperthyroidism, hypothyroidism, goiter, and thyroid cancer) or intake of thyroid medication (e.g. hormone medication and antithyroid medication), data of 2316 KORA individuals (1292 men and 1024 women) aged 32-81 years were analyzed in this study.

The investigations were carried out in accordance with the Declaration of Helsinki, including written informed consent of all participants. All study methods were approved by the Ethics Committee of the 'Bayerische Landesärztekammer' Munich.

Study of Health in Pomerania Data are based on the SHIP-1 (2002-2006), a follow-up of the SHIP baseline study, a population-based cross-sectional survey carried out in West Pomerania between 1997 and 2001. In brief, a sample of adults aged 20-79 years was drawn from population registries. The net sample (without migrated or deceased persons) comprised 6265 eligible subjects. Finally, 4308 subjects participated in the baseline survey. Of those, 3300 subjects $(83.5 \%$ of still living and achievable persons) took part (14). All participants gave written informed consent. The study conformed to the principles of the Declaration of Helsinki as reflected by an a priori approval of the Ethics Committee of the University of Greifswald.

Of the 3300 participants, all men and women with known thyroid disease (e.g. hyperthyroidism, hypothyroidism, goiter, and thyroid cancer) or intake of thyroid medication (e.g. hormone medication and antithyroid medication) were excluded $(n=795$, 24.1\%; 557 women and 238 men). Thus, the present analyses comprised 2505 (1351 men and 1154 women) SHIP participants aged 25-88 years.

\section{Interview and physical examination}

In both studies, trained and certified staff did standardized personal interviews. These interviews included thyroid-related questions. Information concerning medical drug use was also obtained. All participants were asked to bring to the interview all medications taken in the 7 days preceding the examination. In both KORA and SHIP, medication data were obtained online using the IDOM program (online drug database of medication assessment). The medications were categorized according to the Anatomical Therapeutic Chemical classification index.

\section{Ultrasonography of the thyroid}

Both SHIP and KORA performed a collaborative quality management for thyroid ultrasound. Ultrasonography was performed with an ultrasound VST-Gateway with a $5 \mathrm{MHz}$ linear array transducer (Diasonics, Santa Clara, CA, USA) in SHIP and with a ACUSON X300 (Siemens Medical Solutions, Mountain View, CA, USA) or SONOLINE G50 (Siemens Medical Solutions), both with a $5 \mathrm{MHz}$ linear array transducer, in KORA. Thyroid volume was calculated as length $\times$ width $\times$ depth $\times 0.479(\mathrm{ml})$ for each lobe (15). Within and between both studies, the intra- and inter-observer reliabilities were assessed before the start of each study and afterwards annually during the studies; analyses were performed according to Bland \& Altman (16). All measurements of the thyroid volume for within and between study comparisons showed Spearman's correlation coefficients of $>0.85$ and mean differences ( \pm 2 s.D.) of the mean bias $<5 \%(<25 \%)$. Goiter was defined as a thyroid volume of $>18 \mathrm{ml}$ in women and of $>25 \mathrm{ml}$ in men (17). If the echo pattern was not homogeneous, showing small lesions or distinct, diffuse abnormalities in the echotexture of the gland, it was classified as inhomogeneous. Nodular changes exceeding $10 \mathrm{~mm}$ in diameter were defined as nodules. A homogeneous echo pattern with reduced echogenicity was defined as hypoechogenic (10). 


\section{Clinical chemical measurements}

For both studies, laboratory parameters were analyzed in the same laboratory. Serum thyroid-stimulating hormone (TSH) levels were analyzed by immunochemiluminescent procedures (Immulite 2000, Third generation, Diagnostic Products Corporation (DPC), Los Angeles, CA, USA in SHIP and Vista, Siemens, Eschborn, Germany in KORA). The functional sensitivity of the TSH assay was $0.005 \mathrm{mIU} / \mathrm{l}$; the TSH working range was $0.005-100 \mathrm{mIU} / \mathrm{l}$. The (low or high) inter-assay coefficients of variation $(\mathrm{CV})$ were 2.04 or $2.2 \%$ for TSH. Method comparison of the DPC method against the Vista method yielded a high correlation coefficient $(r=0.989)$ and revealed a regression equation according to Passing-Bablok of $y=0.937 x-$ $0.024 \mathrm{mIU} / \mathrm{l}$. All serum TSH levels from SHIP were corrected using this formula. The serum TSH reference range was defined as $0.25-2.12 \mathrm{mIU} / \mathrm{l}$ according to reference limits established in the SHIP region (18). Serum autoantibodies to thyroperoxidase (TPO-Abs) were measured by an enzyme immunoassay (VARELISA; Elias Medizintechnik GmbH, Freiburg, Germany). The functional sensitivity of this assay was $1 \mathrm{IU} / \mathrm{ml}$. The reference range provided by the manufacturer was $<60 \mathrm{IU} / \mathrm{ml}$ for men and $<100 \mathrm{IU} / \mathrm{ml}$ for women. The TPO-Abs status was defined as follows: normal $<60 \mathrm{IU} / \mathrm{ml}$ in men and $<100 \mathrm{IU} / \mathrm{ml}$ in women; elevated $\geq 60 \mathrm{IU} / \mathrm{ml}$ in men and $\geq 100 \mathrm{IU} / \mathrm{ml}$ in women; positive $>200 \mathrm{IU} / \mathrm{ml}$ in both sexes (10).

Urinary iodine concentrations were measured in spot urine samples. Iodine concentrations were evaluated by photometric procedure (Photometer ECOM 6122, Eppendorf, Hamburg, Germany) based on Sandell \& Kolthoff reaction $(19,20)$ in the modification of Lorenz-Wawschinek et al. (21, 22). The calibration range of this method has a detection limit of 1-300 $\mu \mathrm{g} / \mathrm{l}$. Higher concentrated samples were diluted to this range. During the course of the study, the inter-assay CV was $5.2 \%$ with a mean of $103.0 \%$ at the $20 \mu \mathrm{g} / \mathrm{l}$ level.

\section{Statistical analysis}

All calculations were weighted according to the age and gender distribution of the general German population (year 2007) and are reported stratified by study. Continuous variables are described as median and inter-quartile range for each of the age and gender strata. For dichotomous variables, prevalences are reported in percent for each of the age and gender strata. Differences in prevalence between KORA and SHIP were tested by median (continuous outcomes) and logistic regression (dichotomous outcomes) models. Correlations $r$ were reported as Spearman's correlation coefficient (two continuous variables), as Cramer's $\Phi$ (two categorical variables), and as rank biserial correlation coefficient (one continuous and one categorical variable). To account for a possible confounding effect of smoking on the regional differences of thyroid measurements, we calculated two regression models for each of the thyroid measurements: the first model adjusted for study region, age, and sex, and the second model additionally adjusted for smoking status. All calculations were performed using STATA 11.1 (Stata Corporation, College Station, TX, USA).

\section{Results}

Altogether, $24.8 \%$ in KORA and $24.1 \%$ in SHIP had a previously diagnosed thyroid disorder. Among those without a previously diagnosed thyroid disorder, 75.8\% in KORA and $60.7 \%$ in SHIP had an undiagnosed thyroid disorder. When combining thyroid ultrasound findings and out-of-range thyroid hormone values, the overall prevalence of thyroid disorders, diagnosed or undiagnosed, in the studied cohorts was $70.1 \%$ in SHIP (men, 65.0\%; women, $74.9 \%$ ) and 81.5\% (men, 75.7\%; women, $86.8 \%$ ) in KORA.

\section{Urinary iodine concentrations}

The median urinary iodine concentration was $110 \mu \mathrm{g} / \mathrm{l}$ $(64 ; 169 \mu \mathrm{g} / \mathrm{l})$ in SHIP and $151 \mu \mathrm{g} / \mathrm{l}(97 ; 214 \mu \mathrm{g} / \mathrm{l})$ in KORA $(P<0.001)$. In both sexes and all age-groups, iodine concentration was higher in KORA than in SHIP. The median urinary iodine concentration was $124 \mu \mathrm{g} / \mathrm{l}(78 ; 180 \mu \mathrm{g} / \mathrm{l})$ in male SHIP and $152 \mu \mathrm{g} / \mathrm{l}$ $(106 ; 214 \mu \mathrm{g} / \mathrm{l})$ in male KORA participants and $93 \mu \mathrm{g} / \mathrm{l}$ (53; $154 \mu \mathrm{g} / \mathrm{l})$ in female SHIP and $150 \mu \mathrm{g} / \mathrm{l}$ (87; $215 \mu \mathrm{g} / \mathrm{l}$ ) in female KORA participants (Table 1).

\section{Thyroid volume and goiter}

The median thyroid volume was $18.8 \mathrm{ml}$ (14.6; $24.6 \mathrm{ml})$ in SHIP and $17.7 \mathrm{ml}(13.3 ; 24.1 \mathrm{ml})$ in KORA $(P<0.001)$. In almost all age-groups and both sexes, thyroid volume was larger in SHIP than in KORA. The median thyroid volume was $22.4 \mathrm{ml}(17.8$; $27.9 \mathrm{ml})$ in male SHIP and $20.7 \mathrm{ml}(16.2 ; 27.0 \mathrm{ml})$ in male KORA participants; the corresponding values for female participants were $15.6 \mathrm{ml}(12.3 ; 19.6 \mathrm{ml})$ and $14.3 \mathrm{ml}(11.0 ; 18.8 \mathrm{ml})$.

The proportion of goiter was $35.7 \%$ in SHIP and $31.0 \%$ in KORA $(P=0.001)$ and in both populations the proportions were higher in men (SHIP, 37.5\%; KORA, $32.6 \%$ ) than in women (SHIP, 33.6\%; KORA, 29.1\%). In both study regions and sexes, the frequency of goiter increased with age. In males, in the youngest age-group the proportion was $15.0 \%$ (SHIP) and $19.5 \%$ (KORA) compared with $49.7 \%$ (SHIP) and $36.9 \%$ (KORA) in the oldest age-group. In females, the corresponding numbers were 19.0 and $9.5 \%$ in the youngest age-group and 54.1 and $59.3 \%$ in the highest age-group (Tables 2 and 3). 
Table 1 Median iodine concentrations in microgram per liter stratified by sex and study. Data are expressed as median and inter-quartile range.

\begin{tabular}{lcccccc}
\hline & $\mathbf{2 5 - 3 4}$ years & $\mathbf{3 5 - 4 4}$ years & $\mathbf{4 5 - 5 4}$ years & $\mathbf{5 5 - 6 4}$ years & $\mathbf{6 5 - 7 4}$ years & $\mathbf{7 5 - 8 8}$ years \\
\hline Males & & & & & & \\
SHIP & $121(70-184)$ & $117(73-168)$ & $127(80-173)$ & $122(79-187)$ & $135(80-203)$ & $124(72-181)$ \\
KORA & $189(122-238)$ & $148(100-212)$ & $152(115-214)$ & $157(107-213)$ & $152(102-218)$ & $152(107-216)$ \\
Females & & & & & & \\
SHIP & $89(48-162)$ & $92(54-154)$ & $88(48-147)$ & $100(55-167)$ & $94(62-152)$ & $88(51-154)$ \\
KORA & $144(98-234)$ & $146(78-215)$ & $151(88-216)$ & $160(94-221)$ & $142(94-196)$ & $152(96-197)$ \\
\hline
\end{tabular}

\section{Thyroid nodules}

At least one thyroid nodule was more frequently present in KORA than in SHIP participants (KORA, 59.3\%; SHIP, 36.3\%; $P<0.001)$. This was the case in both men (KORA, 54.6\%; SHIP, 32.1\%) and women (KORA, 65.0; SHIP, $40.9 \%$ ). In both studies, the frequency of thyroid nodules increased with age in both men and women and was, in all age-groups, more frequent in women than in men. In males, in the age-group 25-34 years, the proportion was $12.5 \%$ (SHIP) and $30.4 \%$ (KORA) compared with $51.7 \%$ (SHIP) and $68.9 \%$ (KORA) in the 75-88 years age-group. In females, the corresponding numbers were 17.4 and $42.9 \%$ in the youngest agegroup and 72.3 and $86.1 \%$ in the highest age-group (Tables 2 and 3).

\section{Echogenic thyroid pattern}

An inhomogeneous echo pattern was present in $24.9 \%$ of the SHIP and $40.5 \%$ of the KORA participants $(P<0.001)$. It was more frequently seen in male and female KORA participants in all age-groups, except among females aged 75-88 years. A hypoechogenic pattern of the thyroid gland was found in $2.7 \%$ of the SHIP and $7.1 \%$ of the KORA participants. In both regions a hypoechogenic pattern was more frequently seen in women (SHIP, 4.4\%; KORA, 9.8\%) than in men (SHIP, 1.2\%; KORA, 4.8\%). In total, the proportion of ultrasonographic findings (goiter/nodules, inhomogeneous or hypoechogenic pattern of the thyroid gland) was $55.5 \%$ in SHIP and $68.0 \%$ in KORA.

\section{Thyroid function}

The median TSH value was $0.81 \mathrm{mIU} / \mathrm{l}$ (0.56; $1.15 \mathrm{mIU} / \mathrm{l})$ in SHIP and $1.22 \mathrm{mIU} / \mathrm{l}$ (0.84; $1.80 \mathrm{mIU} / \mathrm{l})$ in KORA $(P<0.001)$. In both populations, TSH decreased consistently with age in both men and women. The median TSH value was $1.0 \mathrm{mIU} / \mathrm{l}$ in men and $0.9 \mathrm{mIU} / \mathrm{l}$ in women from the northeast aged 25-34 years; the respective values for men and women from the south were 1.5 and $1.6 \mathrm{mIU} / \mathrm{l}$. In those 75-88 years of age, the median TSH value in SHIP was $0.7 \mathrm{mIU} / \mathrm{l}$ in both sexes, and in KORA $1.1 \mathrm{mIU} / \mathrm{l}$ in men and $1.0 \mathrm{mIU} / \mathrm{l}$ in women (Tables 4 and 5).

In both study regions and all age-groups, the percentage of people with hypothyroidism was higher in males than in females. The frequency of elevated TSH (TSH $\geq 2.12 \mathrm{mIU} / \mathrm{l}$ due to our reference values) was higher in the KORA population, both for men and women and in each age-group (Tables 4 and 5). The overall proportion of elevated TSH for 25- to 88-year-old men was $4.2 \%$ in SHIP and $12.3 \%$ in KORA $(P<0.001)$; the corresponding values for women were 4.5 and $16.1 \%(P<0.001)$.

The prevalence of suppressed TSH $(<0.25 \mathrm{mIU} / \mathrm{l})$ in males was $4.2 \%$ in SHIP and $1.7 \%$ in KORA $(P<0.001)$, while for females it was $3.5 \%$ in SHIP and $1.7 \%$ in KORA $(P<0.009)$. Low TSH was thus more frequently found in northeast than in south Germany. This was seen in all age-groups and both sexes (Tables 4 and 5).

After applying an alternative TSH reference range of 0.3-3.0 mIU/l (23) the analyses arrived at similar regional disparities. While the prevalence of hypothyroidism was $1.5 \%$ in SHIP and $4.1 \%$ in KORA, the

Table 2 Ultrasonographic findings in men stratified by study. Data are expressed as median and inter-quartile range (continuous variables) and as frequency in percentage (dichotomous variables).

\begin{tabular}{lllllll}
\hline & $\mathbf{2 5 - 3 4}$ years & $\mathbf{3 5 - 4 4}$ years & $\mathbf{4 5 - 5 4}$ years & $\mathbf{5 5 - 6 4}$ years & $\mathbf{6 5 - 7 4}$ years & $\mathbf{7 5 - 8 8}$ years \\
\hline Thyroid volume $(\mathrm{ml})$ & & & & & & \\
$\quad$ SHIP & $18.9(15.7-22.4)$ & $20.6(17.4-26.0)$ & $23.2(18.5-28.5)$ & $22.4(18.1-28.2)$ & $26.0(19.8-33.2)$ & $24.9(19.3-35.1)$ \\
KORA & $17.5(15.2-22.1)$ & $18.2(14.7-23.9)$ & $20.7(16.5-28.0)$ & $22.6(17.7-29.0)$ & $22.8(18.1-30.5)$ & $20.6(17.4-29.3)$ \\
Goiter & 15.0 & 31.4 & 40.8 & 37.4 & 53.7 & 49.7 \\
SHIP & 19.5 & 21.6 & 34.2 & 37.2 & 45.1 & 36.9 \\
KORA & 12.5 & 21.4 & 29.5 & 37.3 & 53.3 & 51.7 \\
Thyroid nodules & & 50.7 & 52.0 & 65.0 & 70.4 & 68.9 \\
SHIP & 30.4 & & & & & \\
KORA & & &
\end{tabular}


Table 3 Ultrasonographic findings in women stratified by study. Data are expressed as median and inter-quartile range (continuous variables) and as frequency in percentage (dichotomous variables).

\begin{tabular}{|c|c|c|c|c|c|c|}
\hline & $25-34$ years & $35-44$ years & $45-54$ years & $55-64$ years & $65-74$ years & 75-88 Years \\
\hline \multicolumn{7}{|c|}{ Thyroid volume (ml) } \\
\hline SHIP & $13.8(11.1-16.9)$ & $14.8(12.1-18.4)$ & $15.7(12.3-19.9)$ & $16.4(13.5-20.2)$ & $17.0(12.5-22.0)$ & $18.7(14.7-26.2)$ \\
\hline KORA & $11.3(8.7-13.4)$ & $13.4(10.9-16.9)$ & $14.4(11.0-18.2)$ & $14.5(11.5-20.2)$ & $15.8(11.2-22.0)$ & $19.6(13.9-24.4)$ \\
\hline \multicolumn{7}{|c|}{ 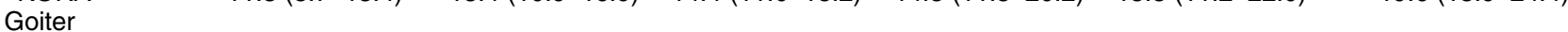 } \\
\hline SHIP & 19.0 & 25.8 & 34.4 & 41.1 & 45.6 & 54.1 \\
\hline KORA & 9.5 & 19.7 & 26.9 & 34.0 & 41.7 & 59.3 \\
\hline \multicolumn{7}{|c|}{ Thyroid nodules } \\
\hline SHIP & 17.4 & 29.2 & 39.8 & 52.2 & 64.1 & 72.3 \\
\hline KORA & 42.9 & 53.7 & 60.6 & 81.2 & 75.8 & 86.1 \\
\hline
\end{tabular}

prevalence of low TSH was $5.2 \%$ in SHIP and $2.0 \%$ in KORA $(P<0.001)$.

\section{Anti-TPO-Abs}

The frequency of positive TPO-Abs $(>200 \mathrm{U} / \mathrm{ml})$ did not differ significantly between KORA and SHIP in males (KORA, $1.5 \%$; SHIP, $1.9 \% ; P=0.548$ ) and females (KORA, 3.9\%; SHIP, 5.5\%; $P=0.111$ ). In both regions and all age-groups, the frequency of positive TPO-Abs was higher in women than in men. In male SHIP participants the proportion of positive TPO-Abs varied between $0.6 \%$ (age-group, 25-34 years) and 3.3\% (age-group, 65-74 years); in female SHIP participants the proportions varied between $1.9 \%$ (age-group, $75-88$ years) and $8.2 \%$ (age-group, 45-54 years); in KORA the respective percentages lay between 0\% (age-group, 25-34 years) and 2.3\% (age-group, 75-88 years) for men and between 2.2\% (age-group, 65-74 years) and 7.5\% (age-group, 55-64 years) for women (Tables 4 and 5).

\section{Correlations}

We detected significant correlations between iodine excretion and serum TSH levels in males and females of the SHIP population, whereas iodine excretion levels were correlated with thyroid volume only in SHIP males (Table 6). In KORA, anti-TPO-Abs were significantly correlated with smoking status in males.

\section{Discussion}

The prevalence of previously diagnosed thyroid abnormalities (about 25\%) was remarkably high and almost similar in both regions. This may be explained not only by the increased awareness regarding thyroid disorders due to information campaigns accompanying the iodine fortification programs but also by information on study findings to the participants. The findings on large thyroid nodules or overt thyroid dysfunction were disclosed to the participants in both KORA and SHIP, which may have been led to further diagnostic follow-ups. The overall prevalence of thyroid abnormalities that were previously diagnosed and undiagnosed thyroid abnormalities combined was $70.1 \%$ in SHIP and $81.5 \%$ in KORA.

This collaborative analysis of population-based data from adults living in northeast and south Germany discovered considerable regional disparities in the frequency of thyroid disorders. Compared with the northeast of Germany, urinary iodine excretion and serum TSH levels were significantly higher in the south. While the proportion of goiter was significantly higher

Table 4 TSH levels and frequencies of high TSH, low TSH, and positive anti-TPO antibodies in men stratified by study. Data are expressed as median and inter-quartile range (continuous variables) and as frequency in percentage (dichotomous variables).

\begin{tabular}{|c|c|c|c|c|c|c|}
\hline & $25-34$ years & $35-44$ years & $45-54$ years & $55-64$ years & $65-74$ years & $75-88$ years \\
\hline \multicolumn{7}{|c|}{ Serum TSH levels (mIU/l) } \\
\hline SHIP & $1.02(0.66-1.36)$ & $0.85(0.61-1.19)$ & $0.74(0.55-1.04)$ & $0.78(0.53-1.16)$ & $0.71(0.47-1.02)$ & $0.69(0.46-1.01)$ \\
\hline KORA & $1.46(0.91-1.75)$ & $1.30(0.92-1.77)$ & $1.14(0.81-1.70)$ & $1.12(0.76-1.54)$ & $1.17(0.80-1.70)$ & $1.06(0.71-1.63)$ \\
\hline \multicolumn{7}{|c|}{ High TSH (TSH $\geq 2.12 \mathrm{mlU} / \mathrm{l})$} \\
\hline SHIP & 7.6 & 3.7 & 2.2 & 4.8 & 4.7 & 2.3 \\
\hline KORA & 8.7 & 12.1 & 11.2 & 13.1 & 13.9 & 11.7 \\
\hline \multicolumn{7}{|c|}{ Low TSH (TSH < 0.25 mlU/l) } \\
\hline SHIP & 1.2 & 2.2 & 4.8 & 3.4 & 5.2 & 7.6 \\
\hline KORA & 2.1 & 0.7 & 1.2 & 1.8 & 2.3 & 2.8 \\
\hline \multicolumn{7}{|c|}{ Positive anti-TPO-antibodies (> $200 \mathrm{U} / \mathrm{ml}$ ) } \\
\hline SHIP & 0.6 & 1.6 & 1.6 & 1.8 & 3.3 & 2.5 \\
\hline KORA & 0.0 & 1.9 & 2.0 & 1.0 & 1.1 & 2.3 \\
\hline
\end{tabular}


Table 5 TSH levels and frequencies of high TSH, low TSH, and positive anti-TPO-antibodies in women stratified by study. Data are expressed as median and inter-quartile range (continuous variables) and as frequency in percentage (dichotomous variables).

\begin{tabular}{|c|c|c|c|c|c|c|}
\hline & $25-34$ years & $35-44$ years & $45-54$ years & $55-64$ years & $65-74$ years & $75-88$ years \\
\hline \multicolumn{7}{|c|}{ Serum TSH levels (mIU/l) } \\
\hline SHIP & $0.88(0.59-1.24)$ & $0.85(0.63-1.21)$ & $0.87(0.60-1.20)$ & $0.82(0.54-1.15)$ & $0.70(0.43-1.08)$ & $0.68(0.46-1.05)$ \\
\hline KORA & $1.63(1.04-2.21)$ & $1.28(0.91-1.80)$ & $1.26(0.88-1.80)$ & $1.33(0.91-1.87)$ & $1.17(0.75-1.76)$ & $0.96(0.62-1.55)$ \\
\hline \multicolumn{7}{|c|}{ High TSH $(T S H \geq 2.12 \mathrm{mIU} / \mathrm{l})$} \\
\hline SHIP & 6.5 & 2.7 & 5.2 & 1.7 & 8.5 & 2.8 \\
\hline KORA & 31.0 & 16.5 & 16.7 & 16.7 & 13.3 & 11.2 \\
\hline \multicolumn{7}{|c|}{ Low TSH (TSH $<0.25 \mathrm{mlU} / \mathrm{l})$} \\
\hline SHIP & 1.7 & 2.2 & 1.3 & 3.4 & 6.8 & 11.4 \\
\hline KORA & 0.0 & 0.0 & 1.7 & 1.0 & 3.2 & 6.2 \\
\hline \multicolumn{7}{|c|}{ Positive anti-TPO-antibodies (>200 U/ml) } \\
\hline SHIP & 5.0 & 5.1 & 8.2 & 4.2 & 5.0 & 1.9 \\
\hline KORA & 2.4 & 3.4 & 3.8 & 7.5 & 2.2 & 2.7 \\
\hline
\end{tabular}

in northeast Germany, inhomogeneous and hypoechogenic echo patterns, as well as nodules, were much more frequently detected in south Germany. The frequency of positive TPO-Abs did not differ significantly between north and south Germany.

The interpretation of these findings has to consider current and past iodine supply to the population. Before the German iodine fortification program became effective, south Germany was more severely affected by iodine deficiency than north Germany. As early as in the late 1940s, palpation studies discovered a higher prevalence of goiter in children living in the mountainous regions of Bavaria compared with children who originally came from the eastern areas of the former German Empire (24). In the 1980s, urinary iodine excretion was shown to be much lower in pregnant women from Bavaria compared with pregnant women from Hamburg (25). In contrast to these historical findings, our study provides evidence for a current status of higher urinary iodine excretion in south than in northeast Germany. Against the background of formerly more severe iodine deficiency status of the south-German population and the voluntary principle of the current German iodine fortification program, it is intriguing to hypothesize that the south-German population has a higher awareness of the potential sequelae of iodine deficiency-related disorders and hence take more care to use iodine-fortificated table salt than the northeast German population.

In comparison with south Germany, the TSH distribution in the northeast German population is shifted towards the left. Thus, TSH reference limits are lower and, consequently, hyperthyroid conditions are more commonly found and hypothyroid conditions are less commonly found in the northeast- than in the south-German population. The different TSH distributions might best be explained by disparities in the iodine supply. Furthermore, selenium status is a relevant factor influencing iodine-related thyroid function (26), and deiodinase polymorphisms distribution in the population (27) may also play a role in the TSH population values. Currently, the better iodine supply may have induced a shift of the TSH distribution towards the right in south compared with northeast Germany. This notion is supported by the higher prevalence of thyroid hypoechogenicity in south compared with northeast Germany and is in line with other studies, which compared the prevalence of thyroid dysfunction in regions with different iodine supply status (3, 28). Hypothetically, the sharper increase of iodine supply over the past 20 years may have contributed to different TSH distributions in northeast and south Germany. In Denmark, a higher prevalence of hypothyroid conditions has been described following the introduction of a mandatory iodine fortification program (29).

In contrast to the parallel prevalence disparities in serum TSH distribution and thyroid hypoechogenicity, we found a higher prevalence of positive anti-TPO-Abs in the northeast- compared with the south-German population. A higher proportion of occupational exposure to radiation (30), different patterns of infectious diseases (31), and higher birth rates in northeast than south Germany (32) may provide explanations.

Given the previously more severe iodine deficiency status, we reasonably could expect higher goiter

Table 6 Correlations between thyroid measurement stratified by sex and study. Correlations $r$ are reported as Spearman's correlation coefficient (two continuous variables), as Cramer's $\Phi$ (two categorical variables), and as rank biserial correlation coefficient (one continuous and one categorical variable).

\begin{tabular}{|c|c|c|c|c|}
\hline \multirow[b]{2}{*}{ Correlation } & \multicolumn{2}{|c|}{ Males } & \multicolumn{2}{|c|}{ Females } \\
\hline & SHIP & KORA & SHIP & KORA \\
\hline lodine - TSH & $-0.13^{*}$ & -0.04 & $-0.07^{\star}$ & -0.03 \\
\hline lodine - thyroid volume & $0.06^{*}$ & 0.03 & 0.05 & 0.00 \\
\hline $\begin{array}{l}\text { lodine - positive anti-TPO- } \\
\text { antibodies }\end{array}$ & -0.05 & 0.16 & -0.06 & -0.09 \\
\hline lodine - smoking status & 0.01 & 0.02 & 0.03 & 0.03 \\
\hline $\begin{array}{l}\text { Positive anti-TPO- } \\
\text { antibodies - smoking status }\end{array}$ & 0.03 & $0.09^{*}$ & 0.00 & 0.03 \\
\hline
\end{tabular}

${ }^{*} P<0.05$. 
prevalence in south compared with northeast Germany before the iodine fortification program became effective (25). In the current analyses, thyroid volumes and goiter prevalence were similar in both populations and even slightly higher in northeast than in south Germany. This finding is in good agreement with the currently higher iodine supply to the south-German population and also argues for beneficial effects of optimized iodine supply, which are not only present in children and adolescents but also in adults.

In contrast, inhomogeneous thyroid echo pattern and nodules were much more often found in adults in south Germany compared with the northeast-German population. There are two major explanations for this finding. First, the high prevalence in the south reflects the history of a more severe iodine deficiency in this area. In contrast to thyroid volume, which is reduced by a better iodine supply (33), the restitution of thyroid nodules might be less likely to occur. Secondly, while all other measurements between both studies were highly standardized, the evaluation of thyroid nodules was not tested for possible inter-study differences. Thus, different ultrasound devices and examiner skills may have contributed to the differences described herein.

The proportion of thyroid ultrasound findings in persons with as yet unknown thyroid disorders was high in this study and accounts for most of the high prevalence of unknown thyroid disorders reported. Previous ultrasound studies from Germany on adults reported inconsistent results regarding the prevalence of thyroid ultrasound findings. While, for example, pathological changes of the thyroid (goiter/nodules and suspected autoimmune thyroiditis) in untreated persons were observed in $70 \%$ of the study conducted by Guth et al. (34), the corresponding proportion was 33\% in the Papillon study (35). A Finnish study conducted on middle-aged women found abnormalities of the thyroid gland as revealed by ultrasound examination in $35.6 \%$ (36). These differences may be due to selection bias and the use of different ultrasound technologies in the studies.

Ultrasound examination is an important method to assess thyroid morphology and to rule out structural diseases. However, for the determination of thyroid function, ultrasound examination is inadequate and the measurement of laboratory parameters is necessary. Thus, ultrasonography can be useful as a supplementary tool to biochemistry for early evaluation of thyroid status.

Age- and sex-related differences found in the present analyses were expected. We observed an age-related decrease in serum TSH levels and increase in structural alterations. This finding is in line with previous studies, which describe that aging is associated with reduced TSH secretion in persons without thyroid disease (37). However, data from the National Health and Nutrition Examinations Survey III (NHANES III) showed that in historically better-iodinated countries TSH values increase with age in persons with no evidence of thyroid disease (38). Very recently, in a longitudinal study on a community-based cohort, it could be confirmed that aging is associated with increased serum TSH concentrations (39). It deserves further investigation regarding the underlying causes for the present finding of a decrease in TSH levels with increasing age.

A higher median urinary iodine concentration in the south- than in the northeast-German population was found in our investigation. While in KORA no differences between males and females with regard to urinary iodine concentrations were present, in SHIP urinary iodine concentrations in all age-groups were higher in men than in women. In male and female KORA participants as well as male SHIP participants, no iodine deficiency was present; however, independent from age, women from the northeast had concentrations below $100 \mu \mathrm{g} / \mathrm{l}$, indicating mild iodine deficiency according to the WHO standard (40). Sex differences in the consumption of iodine-rich food, such as fish or dairy products in the northeastern part of Germany, could explain these findings. In concordance with other studies, women had lower thyroid volumes (41) but more commonly nodules (41) and signs of thyroid autoimmunity $(5,41)$ than men.

Strengths of our study include the population-based design, the large study populations, and the common approach to high standardization of measurements, with the exception of thyroid nodules. The use of data from the first follow-up examinations of both studies might have limited the generalizability of our prevalence findings for each of the investigated populations but may be less important for the comparison between the populations. Recruitment procedures as well as responses to baseline and follow-up examinations were very similar in both KORA and SHIP, so that we do not assume that differential selection has severely biased the comparability of our findings. Further, while the KORA data were collected during 2006-2008, the data for SHIP-1 were collected during 2002-2006. Thus, the data obtained in the study are not exactly coinciding with time in both regions, and consequently a fluctuation in urinary iodine concentrations may occur over time. This fact should be kept in mind regarding the comparisons made between the two studies. Finally, in this study ultrasound examinations were performed using a $5 \mathrm{MHz}$ linear array transducer, which is not the appropriate frequency for superficial organs like the thyroid gland (42). Consequently, the validity of thyroid ultrasound results in particular regarding thyroid nodule detection is uncertain. Therefore, the interpretation of the data is difficult particularly with respect to the association between thyroid nodules and urinary iodine concentrations.

We conclude that there are considerable differences in the prevalence of thyroid disorders in adult populations within one and the same country. The regional differences regarding iodine urinary concentrations, 
TSH values, the prevalence of thyroid volume, goiter, thyroid nodules, and positive anti-TPO-Abs were not confounded by smoking habit. These differences can be explained not only by different regional histories of natural iodine deficiency but also by current differences in the iodine supply under an identical iodine fortification program. Especially, in large countries with iodine fortification programs based on a voluntary principle, the design of monitoring programs should consider possible differences and provide such data to local information campaigns.

\section{Declaration of interest}

The authors declare that there is no conflict of interest that could be perceived as prejudicing the impartiality of the research reported.

\section{Funding}

The KORA research platform and the KORA Augsburg studies are financed by the Helmholtz Zentrum München, German Research Center for Environmental Health $(\mathrm{GmbH})$, which is funded by the German Federal Ministry of Education, Science, Research and Technology and by the State of Bavaria. Thyroid examinations were additionally funded by Sanofi-Aventis in the framework of the Papillon Initiative. SHIP is part of the Community Medicine Research net of the University of Greifswald, Germany, which is funded by the Federal Ministry of Education and Research (BMBF 01ZZ9603 and 01ZZ0103), the Ministry of Cultural Affairs as well as the Social Ministry of the Federal State of Mecklenburg, West Pomerania. Statistical analyses were supported by the German Research Foundation (DFG 955/10-1) and by the Federal Ministry of Nutrition, Agriculture and Consumer's Safety (BMELV 07HSO03).

\section{Acknowledgements}

The contribution to data collection made by field workers, technicians, interviewers, and computer assistants in both studies is gratefully acknowledged.

\section{References}

1 Sawin CT, Castelli WP, Hershman JM, McNamara P \& Bacharach P. The aging thyroid. Thyroid deficiency in the Framingham Study. Archives of Internal Medicine 1985145 1386-1388. (doi:10.1001/archinte.1985.00360080056006)

2 Canaris GJ, Manowitx NR, Mayor G \& Ridgway EC. The Colorado thyroid disease prevalence study. Archives of Internal Medicine 2000 160 526-534. (doi:10.1001/archinte.160.4.526)

3 Laurberg P, Pedersen KM, Hreidarsson A, Sigfusson N, Iversen E \& Knudsen PR. Iodine intake and the pattern of thyroid disorders: a comparative epidemiological study of thyroid abnormalities in the elderly in Iceland and in Jutland, Denmark. Journal of Clinical Endocrinology and Metabolism 199883 765-769. (doi:10.1210/jc. 83.3.765)

4 Delange F. Disorders induced by iodine deficiency. Thyroid 19944 107-128. (doi:10.1089/thy.1994.4.107)

5 Aghini-Lombardi F, Antonangeli L, Martino E, Vitti P, Maccherini D, Leoli F, Rago T, Grasso L, Valeriano R, Balestrieri A \& Pinchera A. The spectrum of thyroid disorders in an iodine-deficient community: the Pescopagano Survey. Journal of Clinical Endocrinology and Metabolism $1999 \mathbf{8 4}$ 561-566. (doi:10.1210/jc.84.2.561)
6 Vitti P, Delange F, Pinchera A, Zimmermann M \& Dunn JT. Europe is iodine deficient. Lancet $2003 \mathbf{3 6 1} 1226$. (doi:10.1016/S01406736(03)12935-2)

7 Kabelitz M, Liesenkötter KP, Stach B, Willgerodt H, Stäblein W, Singendonk W, Jäger-Roman E, Litzenbörger H, Ehnert B \& Grüters A. The prevalence of anti-thyroid peroxidase antibodies and autoimmune thyroiditis in children and adolescents in an iodine replete area. European Journal of Endocrinology $2003 \mathbf{1 4 8}$ 301-307. (doi:10.1530/eje.0.1480301)

8 Meng W, Schindler A, Horack S, Lux E \& Muche A. Renal iodine excretion by students in east Germany. A prospective study 1989 to 1996. Medizinische Klinik 199893 347-351. (doi:10.1007/ BF03044678)

9 Meng WS \& Schindler A. Iodine supply in Germany. In Elimination of Iodine Deficiency Disorders (IDD) in Central and Eastern Europe, the Commonwealth of Independent States and the Baltic States, pp 21-30. Eds F Delange, A Robertson, E McLoughney \& D Gerasimov. (Munich, Germany, 3-6 September 1997, WHO/EURO/NUT/ 98.1), 1998.

10 Völzke H, Lüdemann J, Robinson DM, Spieker KW, Schwahn C, Kramer A, John U \& Meng W. The prevalence of undiagnosed thyroid disorders in a previously iodine-deficient area. Thyroid 200313 803-810. (doi:10.1089/105072503768499680)

11 Meng W \& Scriba PC. Jodversorgung in Deutschland. Deutsches Ärzteblatt 2002 99A 2560-2564.

12 Thamm M, Ellert U, Thierfelder W, Liesenkötter KP \& Völzke H. Iodine intake in Germany. Results of iodine monitoring in the German Health Interview and Examination Survey for Children and Adolescents (KiGGS). Bundesgesundheitsblatt, Gesundheitsforschung, Gesundheitsschutz 200750 744-749. (doi:10.1007/ s00103-007-0236-4)

13 Meisinger C, Strassburger K, Heier M, Thorand B, Baumeister SE \& Rathmann W. Prevalence of undiagnosed diabetes and impaired glucose regulation in 35- to 59-year-old individuals in southern Germany: the KORA F4-Study. Diabetic Medicine 201027 360-362. (doi:10.1111/j.1464-5491.2009.02905.x)

14 Völzke H, Alte D, Schmidt CO, Radke D, Lorbeer R, Friedrich N, Aumann N, Lau K, Piontek M, Born G, Havemann C, Ittermann T, Schipf S, Haring R, Baumeister SE, Wallaschofski H, Nauck M, Frick S, Arnold A, Jünger M, Mayerle J, Kraft M, Lerch MM, Dörr M, Reffelmann T, Empen K, Felix SB, Obst A, Koch B, Gläser S, Ewert R, Fietze I, Penzel T, Dören M, Rathmann W, Haerting J, Hannemann M, Röpcke J, Schminke U, Jürgens C, Tost F, Rettig R, Kors JA, Ungerer S, Hegenscheid K, Kühn JP, Kühn J, Hosten N, Puls R, Henke J, Gloger O, Teumer A, Homuth G, Völker U, Schwahn C, Holtfreter B, Polzer I, Kohlmann T, Grabe HJ, Rosskopf D, Kroemer HK, Kocher T, Biffar R, John U \& Hoffmann W. Cohort profile: the Study of Health in Pomerania. International Journal of Epidemiology $2011 \quad \mathbf{4 0} \quad 294-307$. (doi:10.1093/ije/dyp394)

15 Brunn J, Block U, Ruf G, Bos I, Kunze WP \& Scriba PC. Volumetric analysis of thyroid lobes by real-time ultrasound. Deutsche Medizinische Wochenschrift 1981106 409-414. (doi:10.1055/ s-2008-1070506)

16 Bland JM \& Altman DJ. Regression analysis. Lancet 19861 908-909. (doi:10.1016/S0140-6736(86)91008-1)

17 Gutekunst R, Becker W, Hehrmann R, Olbricht T \& Pfannenstiel P. Ultrasonic diagnosis of the thyroid gland. Deutsche Medizinische Wochenschrift 1988113 1109-1112. (doi:10.1055/s-20081067777)

18 Volzke H, Alte D, Kohlmann T, Lüdemann J, Nauck M, John U \& Meng W. Reference intervals of serum thyroid function tests in a previously iodine-deficient area. Thyroid 200515 279-285. (doi:10.1089/thy.2005.15.279)

19 Sandell EB \& Kolthoff IM. Chronometric catalytic method for the determination of micro quantities of iodine. Journal of the American Chemical Society 193456 1426. (doi:10.1021/ja01321a510)

20 Sandell EB \& Kolthoff IM. Micro determination of iodine by a catalytic method. Microchimica Acta 1937 19-25. (doi:10.1007/ BF01476194) 
21 Lorenz-Wawschinek O, Tiran B, Eber O \& Langsteger W. Photometric determination of iodine in urine. Experimental and Clinical Endocrinology 1994102 (Suppl 2) 357-358.

22 Zöllner H, Kramer A \& Hampel R. Screening for deficiency of iodine. GIT Labor Medizin 199518 330-332.

23 Baskin HJ, Cobin RH, Duick DS, Gharib H, Guttler RB, Kaplan MM \& Segal RL. American Association of Clinical Endocrinologists medical guidelines for clinical practice for the evaluation and treatment of hyperthyroidism and hypothyroidism. Endocrine Practice 20028 457-469.

24 Bauer J. Prophylaxis of struma in children; investigations on 45,818 school children in different counties of southern Bavaria. Medizinische Klinik 195247 530-535.

25 von Reuss $\mathrm{K} \&$ Wieland $\mathrm{OH}$. Iodine deficiency, congenital goiter and congenital hypothyroidism. Results of TSH screening in southern Bavaria. Deutsche Medizinische Wochenschrift 1984109 1918-1921. (doi:10.1055/s-2008-1069479)

26 Arthur JR \& Beckett GJ. Thyroid function. British Medical Bulletin 199955 658-668. (doi:10.1258/0007142991902538)

27 Peltsverger MY, Butler PW, Alberobello AT, Smith S, Guevara Y, Dubaz OM, Luzon JA, Linderman JD \& Celi F. The -258 A/G (SNP rs12885300) polymorphism of the human type- 2 deiodinase gene is associated with a shift in the pattern of secretion of thyroid hormones following a TRH-induced acute rise in TSH. European Journal of Endocrinology 2012166 839-845. (doi:10.1530/EJE11-1073)

28 Teng W, Shan Z, Teng X, Guan H, Li Y, Teng D, Jin Y, Yu X, Fan C, Chong W, Yang F, Dai H, Yu Y, Li J, Chen Y, Zhao D, Shi X, Hu F, Mao J, Gu X, Yang R, Tong Y, Wang W, Gao T \& Li C. Effect of iodine intake on thyroid diseases in China. New England Journal of Medicine 2006354 2783-2793. (doi:10.1056/NEJMoa054022)

29 Vejbjerg P, Knudsen N, Perrild H, Laurberg P, Carle A, Pedersen IB Rasmussen LB, Ovesen L \& Jorgensen T. Lower prevalence of mild hyperthyroidism related to a higher iodine intake in the population: prospective study of a mandatory iodization programme. Clinical Endocrinology 200971 440-445. (doi:10.1111/ j.1365-2265.2008.03493.x)

30 Völzke H, Werner A, Wallaschofski H, Friedrich N, Robinson DM, Kindler S, Kraft M, John U \& Hoffmann W. Occupational exposure to ionizing radiation is associated with autoimmune thyroid disease. Journal of Clinical Endocrinology and Metabolism 200590 4587-4592. (doi:10.1210/jc.2005-0286)

31 Hybenova M, Hrda P, Prochazkova J, Stejskal V \& Sterzl I. The role of environmental factors in autoimmune thyroiditis. Neuro Endocrinology Letters 201031 283-289.

32 Friedrich N, Schwarz S, Thonack J, John U, Wallaschofski H \& Völzke H. Association between parity and autoimmune thyroiditis in a general female population. Autoimmunity 200841 174-180. (doi:10.1080/08916930701777629)
33 Vejbjerg P, Knudsen N, Perrild H, Carlé A, Laurberg P, Pedersen IB, Rasmussen LB, Ovesen L \& Jørgensen T. Effect of a mandatory iodization program on thyroid gland volume based on individuals' age, gender, and preceding severity of dietary iodine deficiency: a prospective, population-based study. Journal of Clinical Endocrinology and Metabolism 200792 1397-1401. (doi:10.1210/jc. 2006-2580)

34 Guth S, Theune U, Aberle J, Galach A \& Bamberger CM. Very high prevalence of thyroid nodules detected by high frequency (13 MHz) ultrasound examination. European Journal of Clinical Investigation 200939 699-706. (doi:10.1111/j.1365-2362. 2009.02162.x)

35 Reiners C, Wegscheider K, Schicha H, Theissen P, Vaupel R, Wrbitzky $\mathrm{R}$ \& Schumm-Draeger PM. Prevalence of thyroid disorders in the working population of Germany: ultrasonography screening in 96278 unselected employees. Thyroid 2004 $11879-880$.

36 Brander A, Viikinkoski P, Nickels J \& Kivisaari L. Thyroid gland: US screening in middle-aged women with no previous thyroid disease. Radiology 1989173 507-510.

37 Mariotti S, Franceschi C, Cossarizza A \& Pinchera A. The aging thyroid. Endocrine Reviews 199516 686-715.

38 Hollowell JG, Staehling NW, Flanders WD, Hannon WH, Gunter EW, Spencer CA \& Braverman LE. Serum TSH, T(4), and thyroid antibodies in the United States population (1988 to 1994): National Health and Nutrition Examination Survey (NHANES III). Journal of Clinical Endocrinology and Metabolism 200287 489-499. (doi:10.1210/jc.87.2.489)

39 Bremner AP, Feddema P, Leedman PJ, Brown SJ, Beilby JP, Lim EM, Wilson SG, O'Leary PC \& Walsh JP. Age-related changes in thyroid function: a longitudinal study of a community-based cohort. Journal of Clinical Endocrinology and Metabolism 201297 1554-1562. (doi:10.1210/jc.2011-3020)

$40 \mathrm{WHO}$ /UNICEF \& ICCIDD. Indicators for assessing iodine deficiency disorders and their control through salt iodization. (WHO/ NUT/94.6), Geneva 1994.

41 Laurberg P, Jorgensen T, Perrild H, Ovesen L, Knudsen N, Pedersen IB, Rasmussen LB, Carlé A \& Vejbjerg P. The Danish investigation on iodine intake and thyroid disease, DanThyr: status and perspectives. European Journal of Endocrinology 2006 155 219-228. (doi:10.1530/eje.1.02210)

42 Ghervan C. Thyroid and parathyroid ultrasound. Medical Ultrasonography 201113 80-84.

Received 6 February 2012

Revised version received 24 May 2012

Accepted 13 June 2012 